\title{
Incremental deformation: A literature review
}

\author{
Daniel Nasulea ${ }^{1, *}$, and Gheorghe Oancea ${ }^{1}$ \\ ${ }^{1}$ Transilvania University of Brasov, Department of Manufacturing Engineering, Mihai Viteazu No.5, \\ Brasov, Romania
}

\begin{abstract}
Nowadays the customer requirements are in permanent changing and according with them the tendencies in the modern industry is to implement flexible manufacturing processes. In the last decades, metal forming gained attention of the researchers and considerable changes has occurred. Because for a small number of parts, the conventional metal forming processes are expensive and time-consuming in terms of designing and manufacturing preparation, the manufacturers and researchers became interested in flexible processes. One of the most investigated flexible processes in metal forming is incremental sheet forming (ISF). ISF is an advanced flexible manufacturing process which allows to manufacture complex 3D products without expensive dedicated tools. In most of the cases it is needed for an ISF process the following: a simple tool, a fixing device for sheet metal blank and a universal CNC machine. Using this process it can be manufactured axis-symmetric parts, usually using a $\mathrm{CNC}$ lathe but also complex asymmetrical parts using CNC milling machines, robots or dedicated equipment. This paper aim to present the current status of incremental sheet forming technologies in terms of process parameters and their influences, wall thickness distribution, springback effect, formability, surface quality and the current main research directions.
\end{abstract}

\section{Introduction}

In the last few decades, the competition between the product manufacturers becomes increasingly tighter. Because of the customers needs, the manufacturers and their supliers have to manufacture new products and to improve them as soon as possible. If in the 20th century the automotive manufacturers, for example, were launching a new car model in about $7 \ldots 10$ years, now, in the 21 th century, they launch new models in about 4 years. That is the reason why the industy is now focused on the flexibles processes, the products are manufactured in small batches, targeting a minimum production cost.

Metal forming is one of the most important industry, 15-20\% GDP comes from this industry [1], playing a significant role in manufacturing and development. The conventional processes from the metal forming industry like drawing, deep drawing, stamping, stretch forming, etc. allow to manufacture large and mass production batches, being very well developed with an high level of automatization and innovation, high productivity, but low flexibility. Due to the market competition, the products batches are smaller and smaller,

\footnotetext{
* Corresponding author: daniel.nasulea@yahoo.com
} 
parts have more complex shapes and the customer requirements are to decrease the products price. In this case, the conventional sheet forming processes are not suitable because of the tool complexity and costs, and because of the high time from design to manufacturing (large die-preparaton time and costs).

In the last years, the researchs were focused on new processes and methods to meet the customer demands, innovative and flexible processes for small batches products with low costs and less time from design to manufacturing. One of the most used processes in metal forming is Incremental Sheet Forming (ISF). It is a relatively new process for sheet metal parts manufacturing, used for small batch production and also rapid prototyping. The conventional sheet metal forming processes depend on a dedicated tool (every part is manufactured with its own tool). The ISF is a flexible „die-less” process, using a universal, simple and low cost tool for more products. The process allows to reduce the time and costs for developing of new products, and it is suitable for small volume production and also for prototypes manufacturing.

In incremental forming, a simple shaped tool produces a local plastic deformation in the sheet, using layered manufacturing principles, converting the part geometry into many layers in forming direction, in each layer, the forming tool follows a two dimensional contour. This step is repeated layer by layer until the final shape of the part is obtained. All this process is numerically controlled by a machine, therefore, when a new shape of the part is required, only the CNC program has to be be changed and maybe also the forming tool, thus, the change are easy to do with small costs in comparison with conventional processes.

The predecessors of incremental sheet forming are the stretch forming and metal spinning process [2]. The ISF combines the advantages of these two predecessors with $\mathrm{CNC}$ technologies and has become one of the most flexible process in sheet metal forming industry.

\section{Advantages and disadvantages of ISF}

In comparison with conventional metal forming processes, ISF has some advantages. They are summarised bellow [1-4]:

- $\quad$ usual parts can be formed directly from CAD data with minimum dedicated tools;

- $\quad$ process does not require either positive or negative dies; it is a dieless process;

- $\quad$ changes in part design dimensions can be easily and quickly modified; the process has

a high flexibility;

- $\quad$ making metal rapid prototypes is normally difficult, but easy with this process;

- $\quad$ small plastic zone and incremental nature of the process contribute to increase

formability, making it easier to use low formability sheets;

- a conventional CNC milling machine or lathe can be used for this process;

- dimensions of the part is limited only by the working area of the used machine;

- necessary forces do not depends on the parts dimensions;

- $\quad$ process is quiet and relatively noise free.

The ISF process has a few disadvantages [1-4]:

- $\quad$ forming time is much longer than classical processes such as drawing;

- $\quad$ process is limited to small-size batch production;

- $\quad$ forming of right angles cannot be done in one step, requires a multi-step process;

- ISF process enables much higher strains. 


\section{Incremental Sheet Forming working principle}

The tooling design for ISF process is simple and it supposes low costs. The main elements needed to implement an ISF process [5] are ilustrated in figure 1. There are five basic elements according to the type of ISF: a blank holder with or without a backing plate, the sheet metal (blank), a clamping plate and a forming tool. As shown in figure 1, the sheet metal blank is clamped on the backing plate or blank holder. The forming tool have three degrees of freedom (translations on $\mathrm{x}, \mathrm{y}$ and $\mathrm{z}$ axis), and rotation around its own axis, following a path programmed by a CNC software. The tool moves around the outer contour from top to bottom, layer by layer decreasing with the predefined vertical increments (steps in $\mathrm{z}$ direction) in contact with the sheet metal, applying force and deforming the blank until the final desired shape was obtained. Therefore, using a simple forming tool and a CNC controlled path can get simple but also complex sheet metal parts. The process is characterized by deformations of a small surface in the contact area between the tool and the blank, and can achieve greater deformation than the conventional processes.

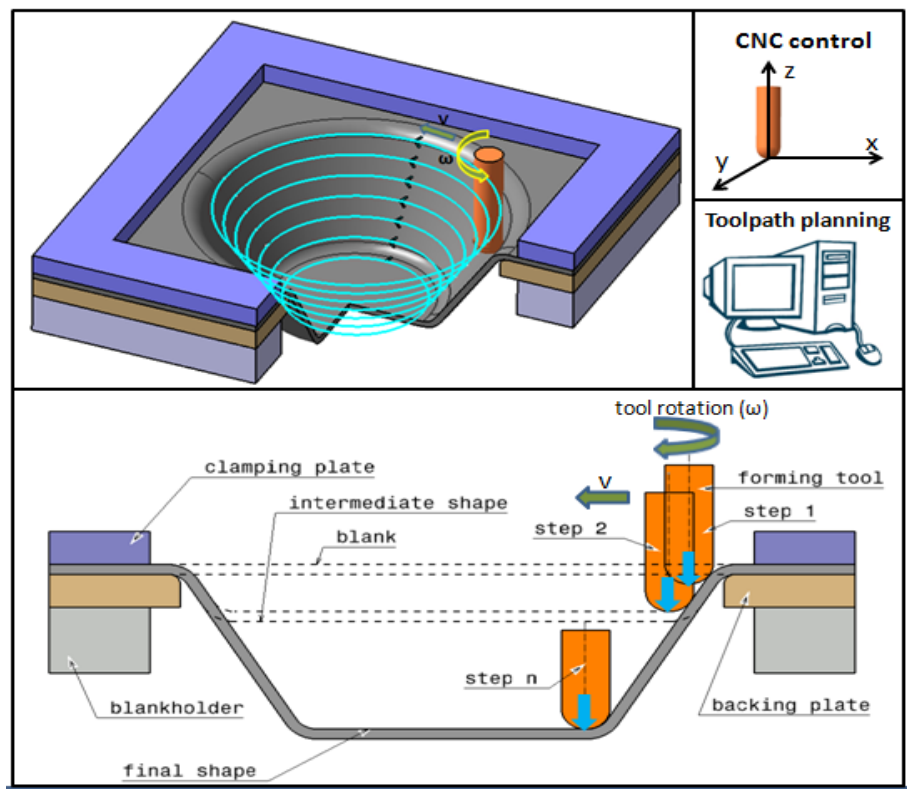

Fig. 1. Principles of ISF processes.

\section{Application of ISF processes}

The ISF processes are used in many domains of metal industry and a lot of situations [3, 5]:

- $\quad$ aerospace industry: instrument panel, body panel, passenger seat cover, and so on;

- $\quad$ automotive industry: door and hood panels, engine cover, and so on;

- $\quad$ electronic industry : cellular phones, hard disk drives, sensors;

- $\quad$ boat industry - ship hull plates;

- $\quad$ products with high level of customization: denture plate, ankle support, metal helmet, health care, and so on;

- low volume or unique products, prototypes or products after-sales;

- $\quad$ architectural - custom made formwork, panels;

- $\quad$ reflectors and casings for lighting; 
- $\quad$ products of national security and defense.

The ISF have been implemented by industrial companies in the process of parts remanufacturing. An example is to produce hoods replacement parts for collection cars (Fig. 2) [6]. The hood was scaned with a 3D scanner, redesigned in CAD system and then remanufactured using the ISF technology. In this way a replacement hood is obtained. Another exemple was the production of some panels for a limited edition of well-known cars, taking some series production parts and reshape some new sharp edges or logo mark using ISF process (Fig. 3) [6].

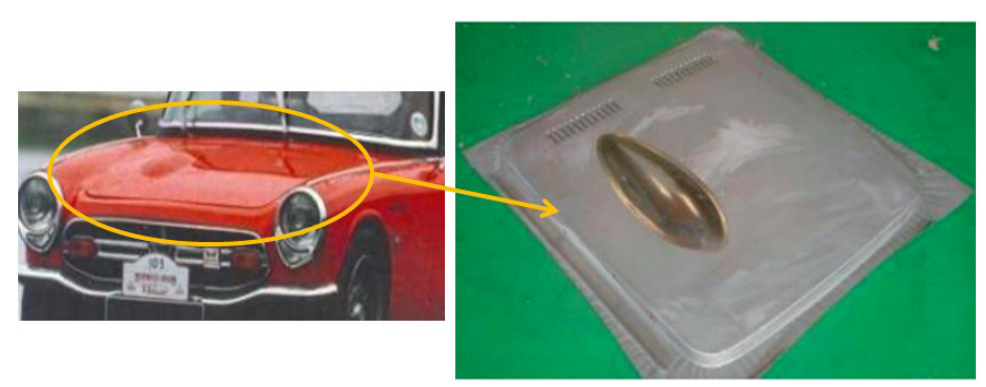

Fig. 2. Hood panel of collection car made with ISF process [6].

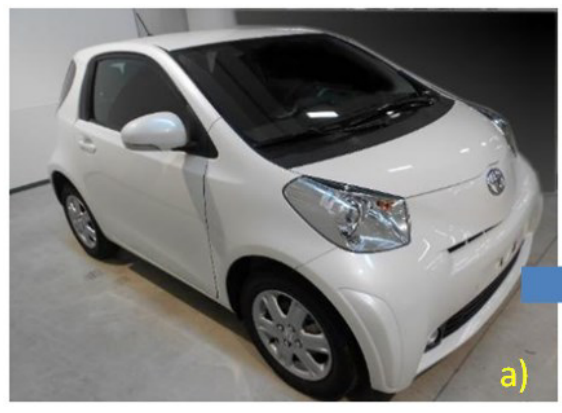

a) Series production car.

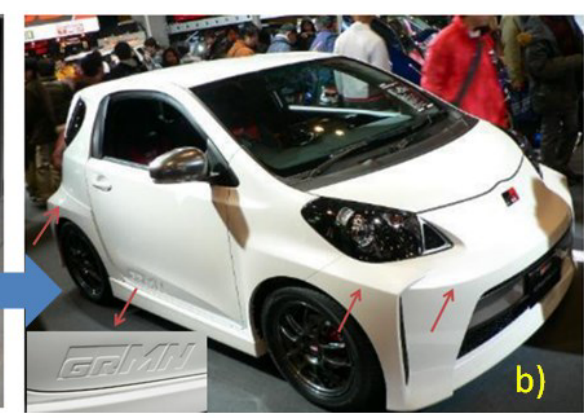

b) Limited edition reshaped with ISF.

Fig. 3. Reshaping of automotive part [6].

\section{Types of incremental forming processes}

The ISF processes can be generaly classified taking into account various aspects. Based on the shape of the manufactured part, the ISF can be [4] :

- $\quad$ symmetric incremental forming (SIF) - for axis-symmetric manufactured parts;

- $\quad$ asymmetric incremental sheet forming (AISF) -for asymmetrical manufactured parts;

From the contact surface between the forming tool and the blank point of view, the ISF can be $[4,7]$ :

- $\quad$ single point incremental forming (SPIF) - one single contact point;

- incremental forming with counter tools - in this type of ISF, another tool offer support from the other side of the blank in the same area with the forming tool;

- two points incremental forming (TPIF): the deformation takes place in more then one point in the same time; it can be with partial die support or with full die support.

In the first two configurations above mentioned, only the tool is moving along the controlled path and the blank holder is stationary. In the third configuration not only the 
forming tool is moving, also the blank holder moves step by step along the tool axis direction, to ensure die support.

\section{Equipments used for ISF}

In many cases, the ISF process supposes the using of a $\mathrm{CNC}$ controlled machines. A minimum 3 axis $\mathrm{CNC}$ machine are needed to control the path of the forming tool along the predefined contours at different levels (Fig. 4). Milling machines are the most commonly used because they allow high speed, large working volumes and good stiffness [4]. For an axis symmetric part (SIF) a CNC lathe is suitable to perform the process in less time, but also a CNC milling machine can be used (Fig. 5) [8].

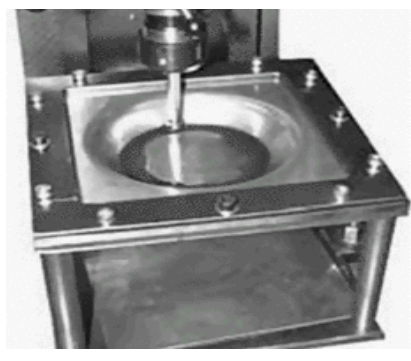

Fig. 4. ISF on CNC milling machine [4].

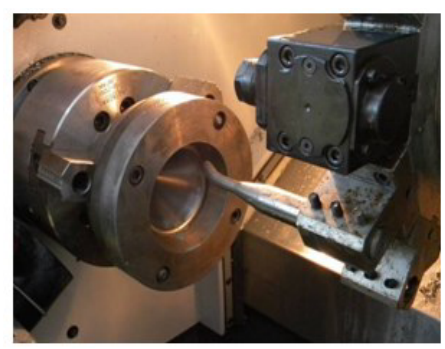

Fig. 5. ISF on CNC lathe [8].

More than that, some researcheres or companies also developed or porposed some machines, who was special builded for ISF process. In 1996, an industrial company developed the firs prototype machine and continued to develop it until 2002 when they started to provide specialized equipment for industry [6]. Another proposal was made by Allwood et al. for a single point incremental sheet forming [9].

Industrial robots are frequently used for ISF process. They have benefits like large working volume and much flexibility than a milling machine, but also some disadvantages, low stifness and low capacity to apply big forces $[4,10]$. Using robots in incremental sheet forming was patented by Tuominen and he describes many configurations with one or two robots, for both SPIF and TPIF technologies [2, 11]. For ISF aro used also Stewart Platforms [4, 12], robotised cells [13] and hexapods [4].

\section{Forming tools}

The most usual tools in incremental forming are the solid tools. A wide variety of solid tools are designed and made by the users taking into account the used equipement. There are not yet standardized tools available on the market $[4,14]$. The solid tools have usualy hemispherical shape and can be straight when it is used on CNC miling machine or for ISF machines (Fig. 6a) [15], and bended when it is used on a CNC lathe (Fig. 6b) [8]. A wide range of tool diameters are used, starting at small diameters of $6 \mathrm{~mm}$ and going up to large tool diameters of $100 \mathrm{~mm}$ for the manufacturing of large parts [14]. Tool diameter is an important factor, influencing on the formability, because of the contact area with the blank. 


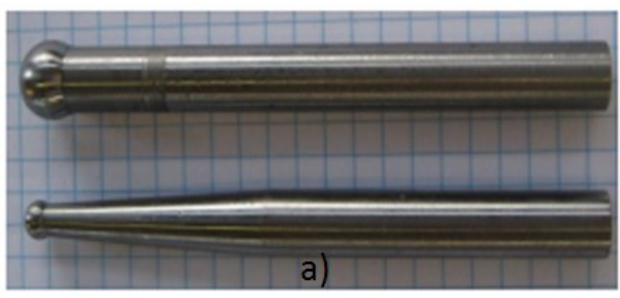

a) Straight tools [15].

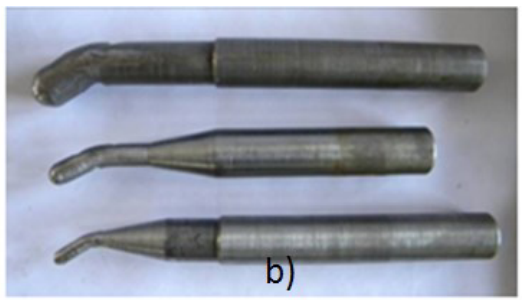

b) Bended tools for lathe utility [8].

Fig. 6. Solid forming tools.

In the last years has been increased the interest of using the flexible tools for ISF process. Iseki [16] and Jurisevic et al. [17] studied the incremental forming using water jet, meen time Geiger and Vollertsen [18] used laser technology like forming tool. The laser technology can be also used to apply a local heating, to improve the material properties, for better formability [19]. Thus, new forming tools are used, water jet and laser forming, but they need future researchs.

\section{Toolpath and tool parameter}

In most of the cases the blank is fixed and the deformation is made by the forming tool that follows a programed path on the contour of the part. The path can be composed by a succession of planar curves that follow the part contour on each step level/increment, or a single spiral contour which makes a passing from one step to next in a smooth ,spiral” way. To genarate the toolpath the CAD model of the part and a CAM software package are needed. Usually, any available CAM software package can be successfully used with same results. Obvious, the CAM softwares are used for cutting process, but can be also used for ISF if is chosed the right strategies. Thus, if the blank is deformed in multiple passes on each level, then one roughing strategy have to be used, because those commands are made to „mill” / deform all the material from inward to outward in multiple steps until the end of the part contour [4]. If the part shape allows to be deformed in a single step, then a finishing strategy can be used, because this is programed to make a single closed loop to the end part contour [4].

Basicaly, two types of toolpath are used: a succession of planar curves (part contour) on each level - level path (Fig.7a) [20], or a spiral toolpath (Fig.7b) [20];

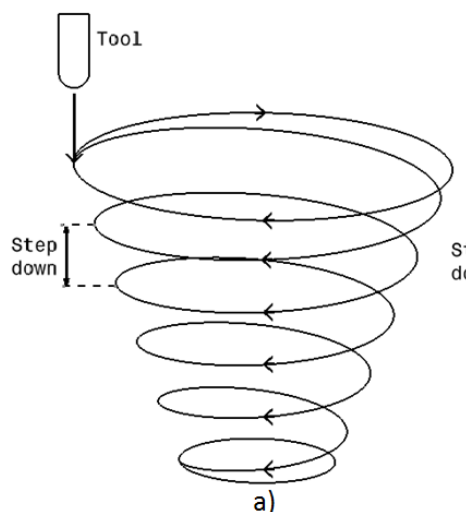

a) Spiral toolpath

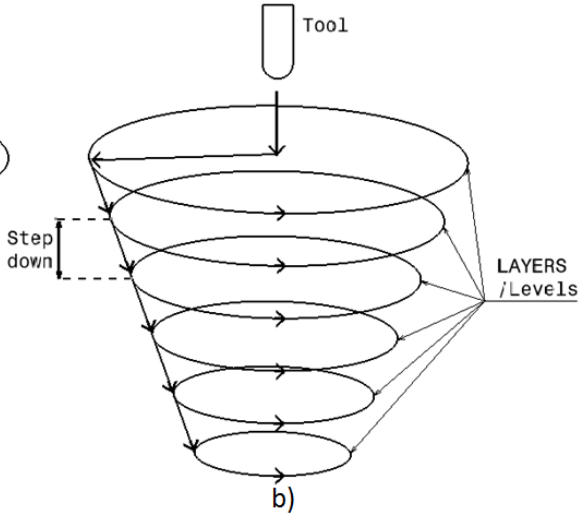

b) Succession of planar curves - level toolpath ;

Fig. 7. Tool toolpaths used in ISF processes [20]. 
Using the level toolpath, on the wall is vissible a trace where the tool passes from layer to layer, while the spiral toolpath is a continuous one where the pitch is equal with the step down and it moves with no traces on the part surface, being frequency utilised. For the level toolpath is needed 2.5 axis milling machine, while for the spiral path is needed minimum 3 axes milling machine. The final part obtained using an ISF process, strongly depends by the tool path generation. It is one of the most important stages which influence the quality, thickness distribution, roughness and deviation because of springback effect. Studies about tool path in ISF were made by Yamashita et al. [21] and Zhou [22]. The paremeters used for tool movement are the same like in the cutting processes, but the values are customized for ISF process. They are feed rates, spindle speed and step down. The feed rates $[\mathrm{mm} / \mathrm{min}]$ have a higher value than in a cutting process [4]. Regarding the spindle speed, a ISF process can be done with or without spindle speed. To obtain a surface with high quality, the blank lubrification have to be used $[4,23]$. The step down (the increment), in fact is the distance between layers in tool axis direction which is usually on $\mathrm{z}$ axis.

\section{Materials}

Incremental sheet forming is basically used for deforming product from metal sheets. The material is chosed according to the needed strength, weight and/or corrosion resistance. In the top of used materials in ISF are alluminum and its alloys. A a lot of researchs regarding diferent topics have been developed [24]. Because of their formability properties and light weight, the brass and copper are two materials frequently used for ISF process [24, 25]. Titanium alloys well-known for their corrosion resistance and high strength and magnesium alloys for their light weight are used in many industries, thus the parts can be also obtained using incremental forming processes [26, 27]. A lot of components from all the industries are made from steel sheets and its derivates, thus these materials are investigated if it is possible to be formed with ISF process, especially cold presing steel like deep drawing and extra deep drawind steel $[24,28]$ There are research to evaluate the possibility to incremental deform the polymer sheets, for a low volume with a low cost production [29].

\section{ISF parts quality}

\subsection{Surface roughness}

Surface quality or surface roughness is one of the important aspects in sheet forming. This is direct influenced by the forming strategy and process parameters like incremental step $\Delta z$, tool radius, draw angle, spendle speed [30]. To measure the surface roughness can be used many indicators $\mathrm{Ra}, \mathrm{Rz}$, etc., but the most useful indicator is $\mathrm{Rz}$, mean peak to valley height [4].

In the literature, it was found that the surface roughness strongly depends on the incremental step size $\Delta z$, when it is increased the result is that surface roughness is also increased [30]. Figure 8 [4] ilustrates the various material ridge hight for various step depth. For part made from aluminium Al 3003, Hagan and Jeswiet defined a mathematical model between incremental depth and peak-to-valley roughness for a 45 degrees wall angle [31]. It was found that the roughness or the ridge height increases exponentially with increesing the incremental step size $\Delta z$. Another researcher, Bhattacharya et al. [32] discovered that the surface quality decreases with step depth increasing, but only till a certain angle. After this angle the surface quality is increased again. 


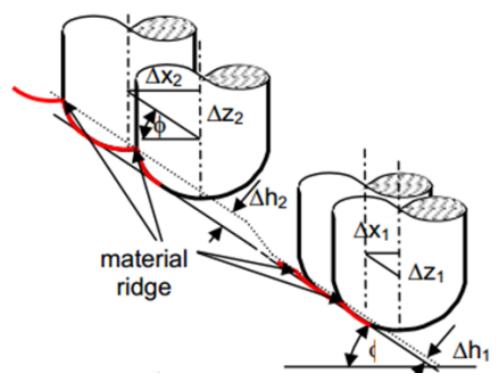

Fig. 8. Influention of step depth on ridge size (roughness) [8].

The tool diameter has also influence on surface roughness. Bhattacharya et al. [32] claim that the surface roughness is decreased when the tool diameter is increased. The tool material and the tool surface quality also influence the final manufactured surface quality. In this way, Oleksik et al. [33] reduced the tool roughness in order to improve the part surface finish, and there were obtained a comparable roughness of the final part with the initial roughness of the titanium alloy sheet.

Another parameter, wall angle or draw angle, influences the surface roughness. When the draw angle is increased, the stretching tension in the material is increased and the sheet metal is strongly stretched, helping to obtain a small value of surface roughness [32]. That meens the deeper products formed with ISF process have a smooth surface quality. It is important to note that the high wall angle can easily lead to failure [30].

Tool rotation or spindle speed has an important effect upon maximum profile height. It was observed that in case of tool with small rotation speed, the surface roughness is decreased. With decreasing, but not stopping the relative motion beetween blank and forming tool, a better surface finish can be obtained than using the high speed rotation [4]. Durante et al. [34] studied the influence of tool rotation on an incremental forming process and he found that the use of rotating tool gives a better surface roughness than a non rotation tool. The diference is about $10 \%$ in advantage of using a rotation tool [30].

\subsection{Springback in ISF}

A shortcoming for ISF processes is the dimensional accuracy of the parts because of the springback effect. Jeswiet et al. [4] appreciates that the most of the world ISF applications impose a dimensional accuracy of less than $1 \mathrm{~mm}$, even less $\pm 0.5 \mathrm{~mm}$ tolerance, while the ISF processes, as Bramley reports [23], the tolerance are $\pm 1.5 \mathrm{~mm}$ for symmetrical parts, and even more, $\pm 2 \mathrm{~mm}$ for the asymmetrical one. Springback effect is the main cause of the dimensional accuracy problems, being one of the most researched topics in ISF processes. It is the geometric change made by a part at the end of the forming process when the part has been released from the forces of the forming tool. In ISF the springback also appear nearby the deformed area, right after the tool just formed it. Therefore, springback affects the dimensional accuracy of the finished part. A lot of researchers investigated this topic and they found many solutions to improve the dimensional accuracy of ISF parts:

- $\quad$ it is indicated to use a backing plate (Fig.1) to support the sheet flange [4, 35];

- using a smaller tool diameter and incremental step depth, the springback can be reduced, as Ambrogio et al.[36] and Oleksik et al. [33] demonstrated;

- Duflou et al. [35] concluded that using a multi-pass toolpath strategy leeds to a better accuracy, minimising the sprigback effect. On the other hand Junchao et al. [37] find that increasing the number of stages the springback becomes higher using a single stage strategy, because of the springback accumulation during each forming stage; 
- $\quad$ some researchers tryed to reduce the springback by correcting the toolpath of the forming tool to adjust the dimensional precision. It was done ,in-process” measurements [38], or out of process was measured the discrepance from the CAD model and the manufactured part and then reload the process with corrected toolpath [4, 39]. Lu et al. [40] presented a new feature-based tool path special algorithm for a better geometric accuracy; - $\quad$ using finite element methods (FEM) to define the springback deviation from the CAD model [39], before the forming process, and redefine the toolpath strategy the precision is improved.

- $\quad$ it was also proposed various models to overcome accuracy problems such as systems with flexible programmable back support structures [41], which are working with multiple and synchronised tools and high complexity.

- heating the sheet metal to improve the mechanical properties of the blank and the plasticity is also used. Duflou et al. [42, 43] uses laser assisted incremental forming with local heating for better formability and accuracy of the part obtained.

\subsection{Wall thickness distribution}

The deformation phenomenon in ISF process is achieved with stretching and redistribution of the material and the final part volume keeps constant with the initial sheet blank, same like shear spinning process. Because the sine law is used in spinning to predict the thickness distribution of the walls, it is taked into consideration also for incremental sheet forming. The sine law materialised that the deformation in this case is the projection of the deformed sheet metal onto the final part surface [14] - see figure 9 [4].

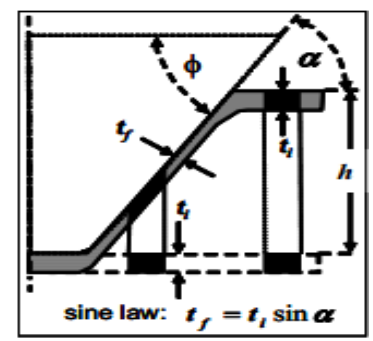

$\mathrm{t}_{\mathrm{f}}$ - final part thickness;

$t_{i}$ - initial sheet thickness;

$\alpha=\phi$ - draw angle;

Fig. 9. Equation for sine law [4].

In recent researchs, a single point incremental forming of a DC04 steel frustum cone on a CNC lathe machine, the sine low predicted the wall thickness in the deformed area with a precision less than \pm 0.1 , without taking into consideration the surface near the fixing area who keeps his thickness [44]. Other researchers discovered that the thickness distribution is nonuniform in all formed area. Young and Jeswiet $[4,45]$ demonstrated this by measuring the thickness distribution on two wall with $30^{\circ}$ and $70^{\circ}$ inclination of a cone made by SPIF process, formed from an $1.21 \mathrm{~mm}$ initial sheet thickness. The first portion near the flange is the most thinned portion of the wall and then there is section with a thickness of about $1 \mathrm{~mm}$. It was calculated the teoretical wall thickness predicted with sine law and compared with the real measurement. It was found that the sine law prediction is bigger than the real wall measured $[4,45]$. Severe thinning appears at high draw angles when also the failure can occur, and the sine law can not be used to predict this unexpected effect. Bambach [46] developed a new model for the process kinematics of ISF to predict sheet thickness distribution. It was compared with experimental results and sine law prediction, and it was found that this new model make better thickness estimates than the sine law. 


\section{Formability}

ISF processes are characterized by a small, localized plastic deformation, which is limited to the contact area between tool and blank. It can be said that the incremental forming processes are characterized by increased material formability [4]. It is well-known that the material behaviour and the formability can be described by the maximum value of the draw angle $\phi \max [4,47,48]$. When the $\phi$ angle increases, the walls of the part become increasingly thinner until the fracure occur. The $\phi \max$ value is considered the maximum angle value up to wich the ISF parts can be processed in good conditions without fracture. Thus, the maximum draw angle $\phi \max$ is a formability benckmark in ISF processes. Knowing the value of $\phi \max$ for diferent material and sheet thickness, can be easy decided at the beginning, if the part can be made in one single pass without failure or shoud be taked other solution like multiple pass or local heating [4].

During the time was made experimental investigations to determine the maximum values $\phi \max$ for diferent materials and sheet thickness and was developed a benchmark product that helps for an easy and sure way to find the $\phi$ max value. The benchmark product shape is a cone base diameter with standard dimensions [49]: diameter D0 $=72 \mathrm{~mm}$, high $\mathrm{H}=40 \mathrm{~mm}$, and the flange $10 \mathrm{~mm}$-figure 10 [49]. Keeping the base cone dimensions, the experiments must be repeated with various degrees of draw angle $\phi$ until the tearing occur. The safe angle value before tearing occurs is in fact the maximum draw angle $\phi$ max.

The formability in ISF is basicaly infuenced by four parameters: sheet thickness, size of the step down, $\Delta \mathrm{z}$, spindle speed and tool forming diameter [4]. It was observed that with increasing the size of the step down $\Delta z$, the sheet formability decreases because of dificults deformation conditions $[31,50]$.

Talking about spindle speed, Micari [50] found that increasing the tool rotation (spindle speed) is influencing in a positive way the formability due to the local heating effect of the relative motion between the blank and the tool. Micari [50] also explains the tool diameter influence upon the formability -using a small diameter, the strain will be concentrated on a small surface under the forming tool, while using a big diameter, the strain tends to distribute on an extended area.

Thus, the conclusion regarding the tool size is that with decreasing the tool radius, the formability is increased [30, 50]. Hirt et al. [39] demonstrated in a study on DC04 material of three diferent sheet thickness, that the draw angle / formability are strongly influenced by the sheet thickness. Because the ISF principle is shear and distribution of the material, keeping the volume constant from blank to final part, with increasing the sheet thickness, thus the material volume increases, and can be obtained bigger deformation degrees, thus greater formability. Kim and Park [51] found similar conclusion about the sheet thickness influence upon the formability, using AA1050-O material.

Another way to describe the formability or the process limit is to consult the forming limit diagram (FLD). The FLD of conventional sheet metal forming processes are inapplicable for ISF [4]. Thus, some researchers developed a dedicated FLC for incremental forming processes. Filice et al. [47] developed a FLC for SPIF which has not only a negative slope but also a high strains achieved by comparison with conventional forming processes (Fig.11) [47]. Young and Jeswiet [4, 48] developed a composite FLD using more slope from diferent geometries parts.

For every geometry resulted an own FLD, witch was combined in one common FLD. Also here a high strain level was obtained. The FLD's developed helps for a better prediction of the formability or the strategy to be used. 


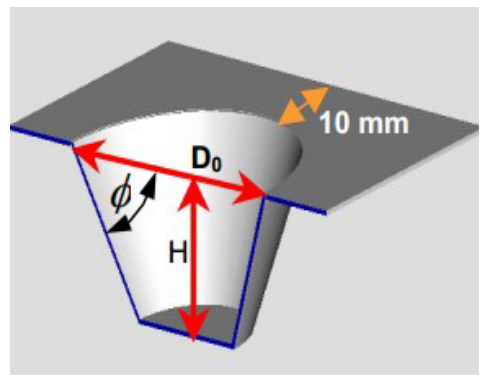

Fig. 10. Benchmark cone dimensions [49].

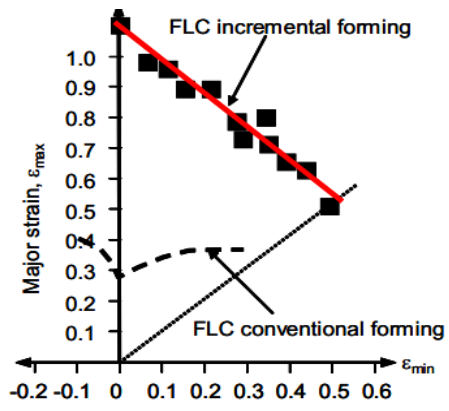

Fig. 11. FLC-ISF vs conventional processes [47].

\section{Forces in ISF}

Forming forces and strain resulted in ISF processes were studied because of their infuences and process limitations. Teoretical researchs was made by Blaga [52] in his $\mathrm{PhD}$ thesis based on the previous researchs made by many authours. It was succeed [52] to determine some teoretical mathematical models for strain and forming forces in ISF.

In ISF processes the tool applies force on the blank. As can be seen in figure 12, there are three components of the force [4, 53]: Fx or Fr (radial force) and Fy or Ft (tangential force) are in horizontal plane, and Fz or Fa (axial force) actions in tool axis direction. Both horizontal components Fx and Fy are repetitive on each level folowed by the tool from top to bottom of the part. It was concluded [54], that the most segnificant value of the force is for $\mathrm{Fz}$, valid for both to SPIF and TPIF.

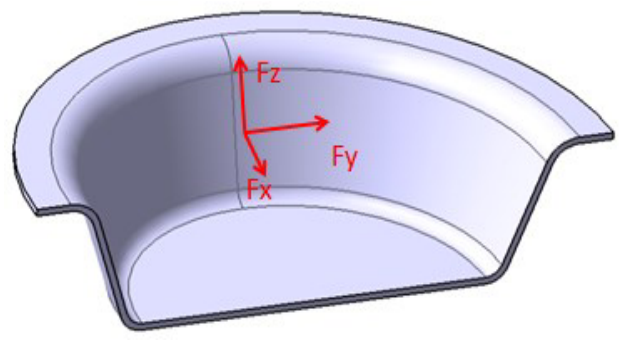

Fig. 12. Force components.

Duflou et al. [55] performed a series of experiments on a reference conical part manufactured by SPIF from five diferent materials. It is measured the forces for differents part configuration and it was concluded with the infuence of sheet thickness, draw angle, tool diameter and step depth $\Delta \mathrm{z}$ on total forces:

- $\quad$ when the sheet thickness is greater, then bigger forces are needed to form the parts;

- $\quad$ increasing the draw angle, the forming forces also increase;

- $\quad$ increasing in step depth $\Delta z$, the forces are slight increase, thus no a segnificant infuence. Therefore the incremental step can be increased to reduce the process time, but with high attention to fracture effect [4];

- increasing the tool diameter, the forming forces will have a high amplitude. Otherwise, the increase in tool diameter is used for a better surface finish of the final parts, but can by a limitation due to high forces and failure can occur [4].

Similar results were found by many authors [20], who research also the sheet orientation influence upon the vertical forming forces. To reduce the forming forces of SPIF process, 
Duflou [42] used a laser beam for a local heating in the contact zone between tool and sheer. Thus, using the rights parameters for ISF processes, it can help to keep control in terms of forming forces.

\section{Stress and strain}

In ISF the tool follow a predefined toolpath and step by step it is stretching when passing over surface. Stress and strain occurs in ISF processes and they represent one of the most important criteria in failure prediction. Many reserchers describe one ISF model, in particular for SPIF, build upon membrane analysis [30, 56, 57], based on investigation of the small cantact area beetween tool and sheet. Jackson and Allwood [58] examinated the ISF mechanism using copper sheets. It was made experiments using both SPIF and TPIF to evaluate the strain distributions through the thickness of the sheets. The measured strain, valid for both configuration processes, shows that the material is streatched and shared in a horizontal plane (perpendicular to tool direction) and only sheared in tool axis direction [30]. The most significant strain component is sheared in the tool axis direction, but all strain components increase passing on every level untill the final part is finished. The wall thickness can not be precise predicted by the sine law in case of increasing stretching and shear perpendicular to the tool direction [30]. Usually in ISF, not only the sheet wich is touched the tool, but also the neighbourhood area to the contact zone is affected, and thus also this area will be analized. Commonly, to analyze the stress strain in ISF, a small element in the contact zone is chosen, as shown in figure 13 [59]. Here are presented the small element analised (in red) and the three stress components $\sigma \mathrm{r}, \sigma \theta$ and $\sigma \varnothing$ along their directions $\mathrm{r}, \theta$ and $\varnothing$. Because the stress along $\theta$ direction causes the circumferential through-thickness shear, it is considered dominant shear efect, while the other two components can be ignored since they do not cause evident plastic deformations [60]. The conclusion regarding the stress evolution is that it increases as the forming tool moves along its own path going to finish, thus the stresses increase with respect to time [1].

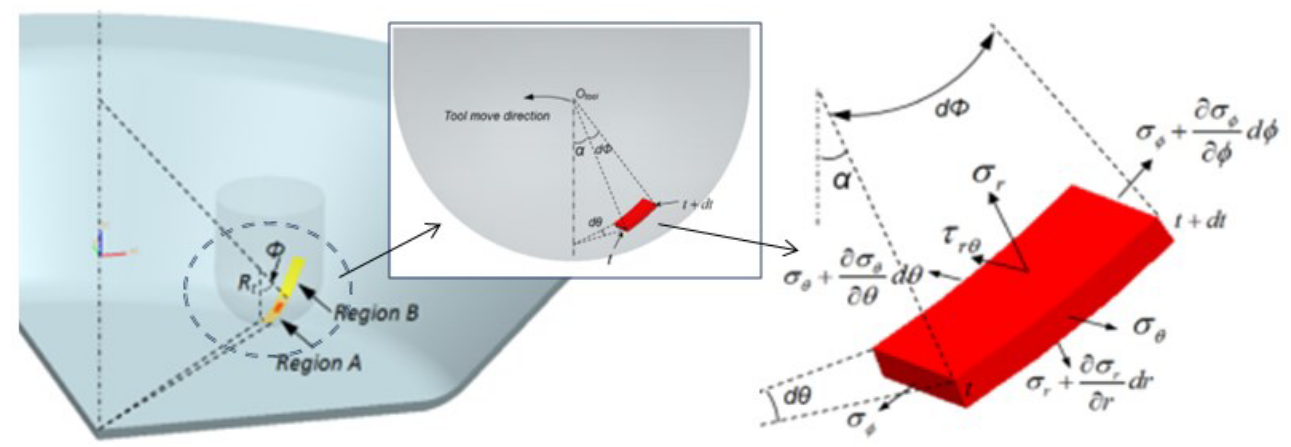

Fig. 13. Small element analized and stress components [59].

\section{FEM simulation in ISF}

Nowadays the finite element method (FEM) is one of the best tools used to improve the part specification from the virtual development phase. Because the traditionals experiments are usualy time consuming and expensive, to reduce the time and costs, the FEM simulation is also used for ISF processes. Usually are used dedicates FEM softwares like Abaqus, LSDyna and Ansys. The main topics studied using FEM simulation are forces analisys [60], 
springback amplitude and toolpath correction [61], deformation analisys [62], influence of the tool parameter and tool path on the deformation behaviour [30] and so on.

To implement a FEM simulation, must be folowed several steps [14]:

- $\quad$ design CAD model of the part and fixing devices;

- $\quad$ simulate and generate the toolpath in CAM software;

- $\quad$ design finite element assemble in FEM software;

- define materials and applying boundary conditions;

- $\quad$ running simulation and result processing.

Because in ISF, the tool is in continuous motion, the FEM simulation in such a model took a huge computation time. To improve this, explicit solver was used, but also time scaling and mass scaling of the model. Also the mesh parameters was analized [14] and was concluded that using a adaptive mesh or small element dimension mesh, better result will be obtained than using a big element dimension.

\section{Future research directions}

ISF processes have been made big steps forward because of its advantages. Worldwide, it has been researched basically topics as follow: forming tool, toolpath and tool parameters, materials, parts quality, formability, forces, stress/strain, and also FEM simulation tools. The ISF processes are not enogh stable and precisely to capture on a large scale the manufacturers' attention. Thus, future investigations are needed. In figure 14 are ilustrated future possible research topics.

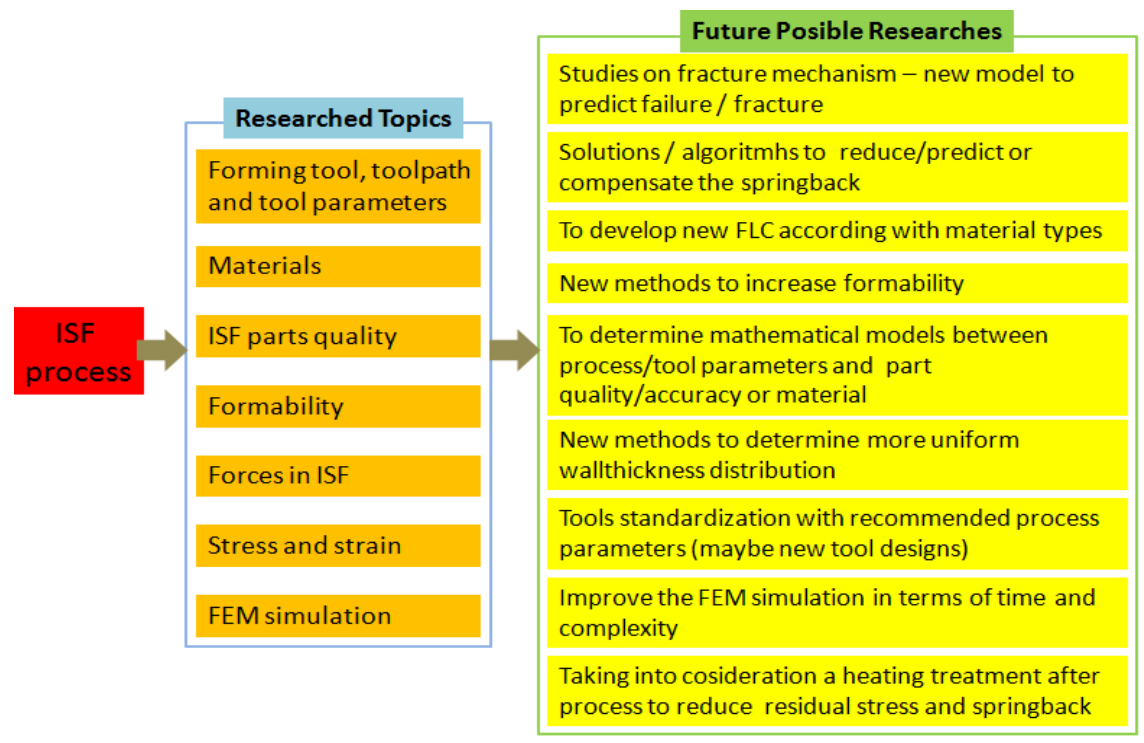

Fig. 14. Actual and future possible research in ISF domain.

\section{Conclusion}

Sheet incremental forming is a dieless forming technology which has been widely studied in the last years. Because it is cheap, easy to implement and it has low tooling cost and a high flexibility, the ISF processes can be used to manufacture unique parts, prototypes or test parts in small batch volumes. It can be also used for manufacturing complex shape 
parts from hard to form materials. The ISF is a time consuming process thus it is not suitable for high volume production. This paper presented the advantages and disadvantages of the process and the domains where it is applicable. It was made a short introduction in ISF processes, talking about the working principle, and the types of ISF. A wide range of equipment can be used to implement one ISF process: CNC lathe (only for axis-symmetric parts), CNC milling machine, industrial robots, Stewart platforms, hexapods, but also dedicates equipment created by various manufacturers. The main topics investigated by the researchers were discussed, and the results for each topic on ISF were presented: forming tool, tool parameters and toolpath, materials used to be deformed, ISF parts quality (surface roughness, wall thickness distribution, springback and accuracy), formability, stress and strain, and forces in ISF. In conclusion the Incremental Forming processes have been made big step forward in rapid manufacturing of sheet metal prototypes. Future researchs will be focused on: fracture mechanism, solution to reduce/predict or compensate springback, development of new FLC and methods to increase formability, mathemathical models between process/tool parameters and parts quality, wallthickness distribution, tools standardization, FEM simulation and maybe implementation of a heating treatment after process to reduce residual stress or springback.

\section{References}

1. Y. Kumar, S. Kumar, Adv.in Mat. Forming and Joining 5th International and $26^{\text {th }}$ All India Manufacturing Technology, Design and Research Conference, AIMTDR 2014, 29 (2014)

2. W.C. Emmens, G. Sebastiani, A.H. van den Boogaard, J. Mater. Process. Technol., 210 (8), 981 (2010)

3. M. Oraon, V. Sharma, AMAE Int. J. on Production and Industrial Engineering, 1(1), 31 (2010)

4. J. Jeswiet, F., Micari, G. Hirt, A. Bramley, J. Duflou, J. Allwood, CIRP Annal Manuf. Technol. 54(2), 88 (2005)

5. J. Jeswiet, M. Geiger, U. Engel, M. Kleiner, M. Schikorra, J. Duflou, R. Neugebauer, P. Bariani, S. Bruschi, CIRP J. Manuf. Sci. Technol., 1, 2 (2008)

6. M. Amino, M. Mizoguchi, Y. Terauchi, T. Maki, $11^{\text {th }}$ ICTP, 81, 54 (2014)

7. L. Lihui, L. Kangning, G. Cai, X. Yang, C. Guo, G. Bu, Manufacturing Rev., 1, 9 (2014)

8. I. Neagoe, A. C. Filip, M. A. Vasiloni, AMM., 371, 168 (2013)

9. J. M. Allwood, N. E. Houghton, K. P. Jackson, AMR, 6-8, 471 (2005)

10. H. Meier, O. Dewalt, J. Zhang, Steel Res. Int., 76(2-3), 167 (2005)

11. T.Tuominen, Method and apparatus for forming three-dimensional shapes in a sheet metal, Patent EP 1560668 A1 (2004)

12. N. D. Joao Torrao, A. F. Jorge Ferreira, J. Ricardo Alves de Sousa, $11^{\text {th }}$ Port. Conf. on Autom. Control, 321, 292 (2014)

13. M. Callegari, D. Amodio, E. Ceretti, C. Giardini, Industrial Robotics: Progrming, Simulation, and Application (edited by Low Kin Huat, Intech Open Science, 493, 2006)

14. D. H. Nimbalkar, V. M. Nandedkar, IJERA, 3(5), 39 (2013)

15. Le Van Sy, Modeling of single point incremental forming process for metal and polymeric sheet, $\mathrm{PhD}$ thesis, University Of Padova, Italy, 2009

16. H. Iseki, JSME INT J C-MECH SY, 4, 486 (2001)

17. B. Jurisevic, K. C. Heiniger, K. Kuzman, IDDRG, 139 (2003)

18. M. Geiger, F. Vollertsen, Annals of CIRP, 42(1), 301 (1993)

19. A. Mohammadi, H. Vanhove, A. Van Bael, J. Duflou, AIP Conference Proceedings, 1567(1), 864 (2013)

20. Z. Liu, Y. Li, P.A. Meehan, Int. J. Precis. Eng. Manuf., 14(11), 1891 (2013)

21. M. Yamashita, M. Gotoh, S-Y. Atsumi, J. Mater. Process. Technol., 199(1-3), 163 (2008)

22. L. R. Zhou, Adv. Mater. Res., 239-242, 940 (2011)

23. A. N. Bramley, Incremental sheet forming process for small batch and prototype parts, in IdeeVision-Innovation, edited by F. Vollersten and M. Kleiner, Verlag Meisenbach, 95 (2001)

24. L. Pekka, V. Tapio, S. Mika, Physics Procedia, 78, 312 (2015) 
25. D. Fritzen, A. Daleffe, J. Castelan, L. Schaeffer, Key Eng. Mater, 554-557, 1419 (2013)

26. A. Daleffe, L. Schaeffer, D. Fritzen, J. Castelan, Key Eng. Mater, 554-557, 195 (2013)

27. R. Hino, K. Kawabata, F. Yoshida $11^{\text {th }}$ ICTP, 81, 2330 (2014)

28. S. Kurra, S. P. Regalla, J. Mater. Res. Technol., 3(2), 158 (2014)

29. P.A.F. Martins, L. Kwiatkowski, V. Franzen, A.E. Tekkaya, M. Kleiner, CIRP Ann. Manuf. Technol., 58(1), 229 (2009)

30. S. Gatea, H. Ou, G. McCartney, Int. J. Adv. Manuf. Technol., 87(1), 479 (2016)

31. E. Hagan, J. Jeswiet, J. Eng. Manuf., 218(Part B), 1307 (2004)

32. A. Bhattacharya, K. Maneesh, N. Venkata Reddy, L. Cao, J. Manuf. Sci. Eng., 133(6), 061020 (2011)

33. V. Oleksik, A. Pascu, C. Deac, R. Fleacă, O. Bologa, G. Racz, Int J Mater Form, 3(S1), 935 (2010)

34. M. Durante, A. Formisano, A. Langella, F. M. Capece Minutolo, J. Mater. Process. Technol., 209(9), 4621 (2009)

35. J. R. Duflou, B. Lauwers, J. Verbert, Y. Tunckol, H. De Baerdemaeker, 8th ESAFORM Conf. on Material Forming, 675 (2005)

36. G. Ambrogio, L. Filice, L. Fratini, F. Micari, Proc. of the $6^{\text {th }}$ Conference ESAFORM., 175 (2003)

37. L. Junchao, P. Geng, J. Shen, Int. J.Adv. Manuf. Technol., 68(9-12), 2637 (2013)

38. G. Ambrogio, L. De Napoli, L. Filice, M. Muzzupappa, Proc. of 7th ASME ICSDA, 3, 339 (2004)

39. G. Hirt, J. Ames, M. Bambach, R. Kopp, Annals of CIRP, 53, 203 (2004).

40. B. Lu, J. Chen, H. Ou, J. Cao, J. Mater. Process. Technol., 213(7), 1221 (2013).

41. H. Meier, V. Smukala, O. Dewald, J. Zhang, Proceedings of the 12th International Conference on Sheet Metal, 344, 599 (2007).

42. J. R. Duflou, B. Callebaut, J. Verbert, H. De Baerdemaeker, CIRP Ann. Manuf. Technol., 56(1), 273 (2007).

43. J, R. Duflou, B. Callebaut, J. Verbert, H. De Baerdemaeker, Int. J. Mach. Tools Manuf., 48(5), $543(2008)$.

44. I.Neagoe, I. Neagoe, A. C. Filip, A. Manolescu, AMM., 657, 142 (2014).

45. D. Young, J. Jeswiet, IMECHE part B, J. of Eng. Manuf., 218( B11), 204 (2004).

46. M. Bambach, J. Mater. Process. Technol., 210, 1562 (2010).

47. L. Filice, L. Fantini, F. Micari, Annals of the CIRP, 51, 199 (2002).

48. D. Young, J. Jeswiet, IMECHE part B, J. of Eng. Manuf., 219, part B, 1-6 (2005).

49. F. Micari, G. Ambrogio, A common shape for conducting incremental forming tests, $1 \mathrm{st}$ Incremental Forming Workshop, University of Saarbrucken, (2004).

50. F. Micari, Single Point Incremental Forming: recent results, Seminar on Incremental Forming, Cambridge University (2004).

51. Y. H. Kim, J. J. Pack, J. Mater. Process. Technol., 130-131, 42 (2002).

52. A. Blaga, Contributions to the incremental forming of thin metal sheets, $\mathrm{PhD}$ thesis - abstract, "Lucian Blaga" University Of Sibiu, Romania (2011).

53. R. Aerens, P. Eyckens, A. Van Bael, J. R. Duflou, Int. J. Adv. Manuf. Technol., 46, 968 (2009).

54. J. Jeswiet, J. Duflou, A. Szekeres, AMR., 6-8, 449 (2005).

55. J. R. Duflou, A. Szekeres, P.Vanherck, AMR., 6-8, 441 (2005).

56. M. Silva, M. Skjoedt, P. Martins, N. Bay, Int. J. Mach. Tools Manuf., 48, 73 (2008).

57. P. A. F. Martins, N. Bay, M. Skjoedt, M. B. Silva, CIRP Ann. Manuf. Technol., 57(1), 247 (2008).

58. K. Jackson, J. Allwood, J. Mater. Process. Technol., 209(3), 1158 (2009).

59. B. Lu, Y. Fang, D.K. Xu, J. Chen, H. Ou, N.H. Moser, J. Cao, Int. J. Mach. Tools Manuf., 85, 14 (2014).

60. F. M. C. Minutolo, M. Durante, A. Formisanom, A. Lagella, 2nd I*PROMS Virtual International Conference, 229 (2006).

61. J. Mo, F. Han, P. Gong, Int. J. Adv. Manuf. Technol., 64 (9), 1239 (2012).

62. H. Iseki, J. Mater., Process. Technol., 111(1-3), 150 (2001). 